\title{
Gas-Phase Base-Catalyzed Claisen-Schmidt Reactions of the Acetone Enolate Anion with Various Para-Substituted Benzaldehydes
}

\author{
George W. Haas* \\ Department of Chemistry, University of Nebraska-Lincoln, Lincoln, Nebraska, USA \\ Michael L. Gross \\ Department of Chemistry, Washington University, St. Louis, Missouri, USA
}

\begin{abstract}
Substituent effects were determined for the gas-phase base-catalyzed Claisen-Schmidt reaction of the acetone enolate anion and various para-substituted benzaldehydes. Under chemical ionization conditions, the adduct for the reaction was detected and the fraction of adduct that is tetrahedral was determined. The Hammett constants for the substituents correlate the fraction of the adduct population that is tetrahedral. The fraction of tetrahedral intermediate is greatest for those systems in which the negative charge is most highly stabilized. The structures of the adducts are determined on the basis of collisionally activated decomposition mass spectra. These spectra show that both the adducts of the ion-molecule reactions and deprotonated reference compounds, which have a structure that is similar to the tetrahedral intermediate, decompose by elimination of water and by a retro-aldol reaction. The adducts formed from the ion-molecule reactions show a greater propensity to reform the acetone enolate, whereas the deprotonated reference compounds eliminate $\mathrm{H}_{2} \mathrm{O}$ readily. The reaction constant $\rho$ from the Hammett correlation is +1.6 , which substantiates that the production of tetrahedral intermediates is facilitated by electron-withdrawing substituents. (J Am Soc Mass Spectrom 1996, 7, 82-92)
\end{abstract}

$\mathrm{T}$ The first base-catalyzed aldol-condensation reaction was carried out in 1880 by Schmidt [1], who reacted furfural and acetaldehyde. Schmidt also investigated the reaction of furfural and acetone, which later became known as the Claisen-Schmidt condensation [2] (a condensation between an aldehyde and a ketone), and that reaction is the first example of a mixed-aldol or crossed-aldol condensation.

The aldol condensation is important in biology because it is involved in the biosynthesis of many significant natural products, which include the products of the life-sustaining dark reactions of photosynthesis. As early as 1887 , Fischer and Tafel [3] studied the photosynthesis product fructose, which was generated in the aldol reaction of an enzyme-catalyzed process.

In the synthetic-organic field, the venerable aldol condensation has been the subject of renewed interest during the last two decades [4] owing to the discovery that the stereochemistry can be controlled by the use of preformed enolates [5]. The aldol condensation is one of the most useful stereoselective reactions among the

Address reprint request to Professor Michael L. Gross, Department of Chemistry, Washington University, 1 Brookings Drive, St. Louis, MO 63130.

- Current address: Helene Curtis, 3100 Golf Road, Rolling Meadows. IL 60008-4009. carbon-carbon bond-forming processes [6]; it enables the synthesis of larger molecules (e.g., antibiotics [7]) with two new functional groups from smaller building blocks of molecules.

The commonly accepted mechanism $[5,8]$ for the general base-catalyzed aldol reaction in solution involves the addition of an $\alpha$-carbon of one aldehyde or ketone molecule to the carbonyl carbon of another (see Scheme I). The entire system reaches equilibrium, and the reverse reaction, which is known as the retro-aldol reaction, reforms reactants.

A mechanistic explanation for the stereoselectivity when preformed enolate derivatives are used for aldol reactions was proposed by Zimmerman and Traxler [5i], who invoked a six-membered transition state. Although this simple mechanism has received support since it was proposed in 1957, recent studies indicate there are many complexities that require that alternate or modified mechanisms be considered [5d].

Although the liquid-phase aldol condensation has been the subject of an enormous amount of study, only since the 1970s have nucleophilic substitutions and additions to carbonyl centers of negative ion-molecule reactions in the gas phase $[9,10]$ received much attention. The gas phase provides an opportunity to explore the intrinsic properties of ionic species and to investi- 


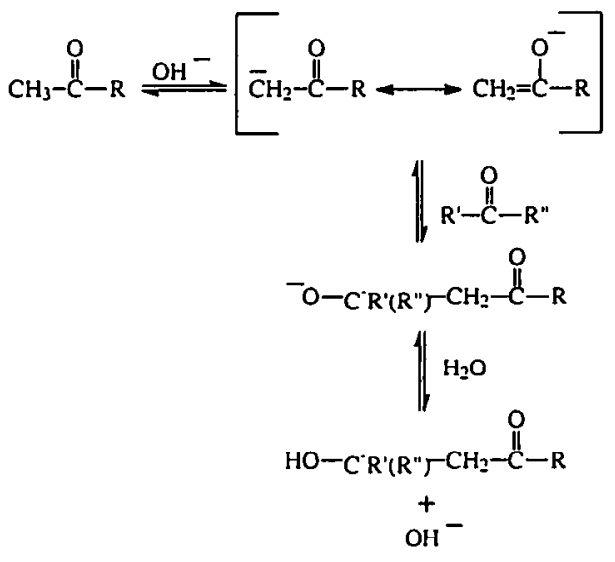

Scheme I

gate ionic intermediates that exhibit high reactivity and are not stable in solution [11]. An underlying problem, however, is to sort out competing pathways involved in the ion-molecule reactions, because only ionic products are detected. One way to elucidate the reaction pathway is with "chemical probes," which are neutral reagents that, when reacted with an nucleophile such as the acetone enolate, yield ionic products that can be used to distinguish between carbon and oxygen attack [12]. Brickhouse and Squires [13] used perfluorinated propene and 6,6-dimethylfulvene, Nibbering and co-workers [14] utilized perfluorinated aromatics, and Brauman and co-workers [15] employed trifluoroacetyl chloride to separate competing pathways in gas-phase reactions of nucleophiles.

Nevertheless, only a few base-catalyzed aldol condensations have been characterized in the gas phase. Bouchoux and Hoppilliard [16] and Bowie and coworkers [17] reported the gas-phase aldol reaction of acetone. Gross and co-workers [18, 19] investigated both the gas-phase reactions of the acetone and acetaldehyde enolates [18] with their respective neutrals and the Reformatsky condensations [19] of the ethylacetate enolate that reacted with acetyldehyde or acetone.

In this article, we present the results of the gas-phase base-initiated Claisen-Schmidt reactions [20] of acetone with various para-substituted benzaldehydes and we probe the nature of the covalent adducts as a function of the Hammett $\sigma_{p}$ substituent parameter. Variation of the substituents of the benzaldehyde-acetone system and use of the Hammett correlation [21] allow us to determine the nature of the adducts and the extent of stabilization that occurs in the formation of tetrahedral intermediates that eliminate $\mathrm{H}_{2} \mathrm{O}$.

\section{Results and Discussion}

\section{Formation of the Adduct}

The product of expected mass for the base-catalyzed Claisen-Schmidt reaction is found when the symmetri- cal acetone enolate, formed by abstraction of $\mathrm{H}^{+}$by $\mathrm{CH}_{3} \mathrm{O}^{-}$, reacts in the gas phase with various benzaldehydes substituted at the para position with $-\mathrm{NO}_{2}$, $\mathrm{Br}-, \mathrm{Cl}-,-\mathrm{SCH}_{3}, \mathrm{H}-,-\mathrm{CH}_{3},-\mathrm{OCH}_{3}$, and $-\mathrm{N}\left(\mathrm{CH}_{3}\right)_{2}$. The nucleophilic-addition adducts, which are formed with excess energy and have little chance to survive until detection without some means of stabilization (e.g., collisions or radiative emission), are collision-stabilized under the conditions of a chemical ionization $(\mathrm{CI})$ source at $\sim 0.1$ torr $(13 \mathrm{~Pa})$. The structure and chemical properties of the collision-stabilized adducts from the gas-phase ion-molecule reactions were studied by examination of both their metastableion [22] and collisionally activated decomposition [23] mass spectra. The former indicate the low energy fragmentation pathways whereas the latter are a measure of the high energy processes. The nature of the adducts was established by comparison of their properties with those of the deprotonated reference compounds, which were prepared by proton abstraction from suitable neutral $\beta$-hydroxy ketones.

\section{Metastable-Ion Studies}

Under low energy conditions, both the adduct and reference ions decompose by elimination of $\mathrm{H}^{\circ}$ and $\mathrm{H}_{2} \mathrm{O}$, as well as by formation of the $m / z 57$ ion (presumably the acetone enolate). The nitro-containing adduct and reference ions also decompose by the loss of $47 \mathrm{u}$, which probably corresponds to $\mathrm{HNO}_{2}$. However, the product ions for both the adducts and the deprotonated reference compounds are of low abundance, which makes accurate assignment of relative abundances difficult. Despite the low abundances, we conclude that the metastable-ion (MI) mass spectra of the adduct and deprotonated reference compounds are similar except for the relative abundances of $\mathrm{H}_{2} \mathrm{O}$-loss and the retro-aldol product ions; $\mathrm{H}_{2} \mathrm{O}$ elimination is attenuated and the retro-aldol product is augmented for the adducts of the ion-molecule reactions compared to the $(\mathrm{M}-\mathrm{H})^{-}$ions of the reference compounds.

\section{Collisionally Activated Decomposition Studies}

The collision-activated decomposition (CAD) mass spectra of the adduct and the appropriate deprotonated reference compounds (see Figures 1 and 2 for example CAD spectra) reveal a wealth of structural information and show a considerable increase of the abundances of product ions compared to those seen in the MI mass spectra. Both the adduct and the corresponding reference anions produce the retro-aldol product (the acetone enolate), give fragment ions that are expected for the particular para substituent, lose neutral acetone to form (in low abundance) the anion of the para-substituted benzaldehyde, and eliminate $\mathrm{H}_{2} \mathrm{O}, \mathrm{H}$; and $\mathrm{H}_{2}$ (see Table 1). The data for losses of 


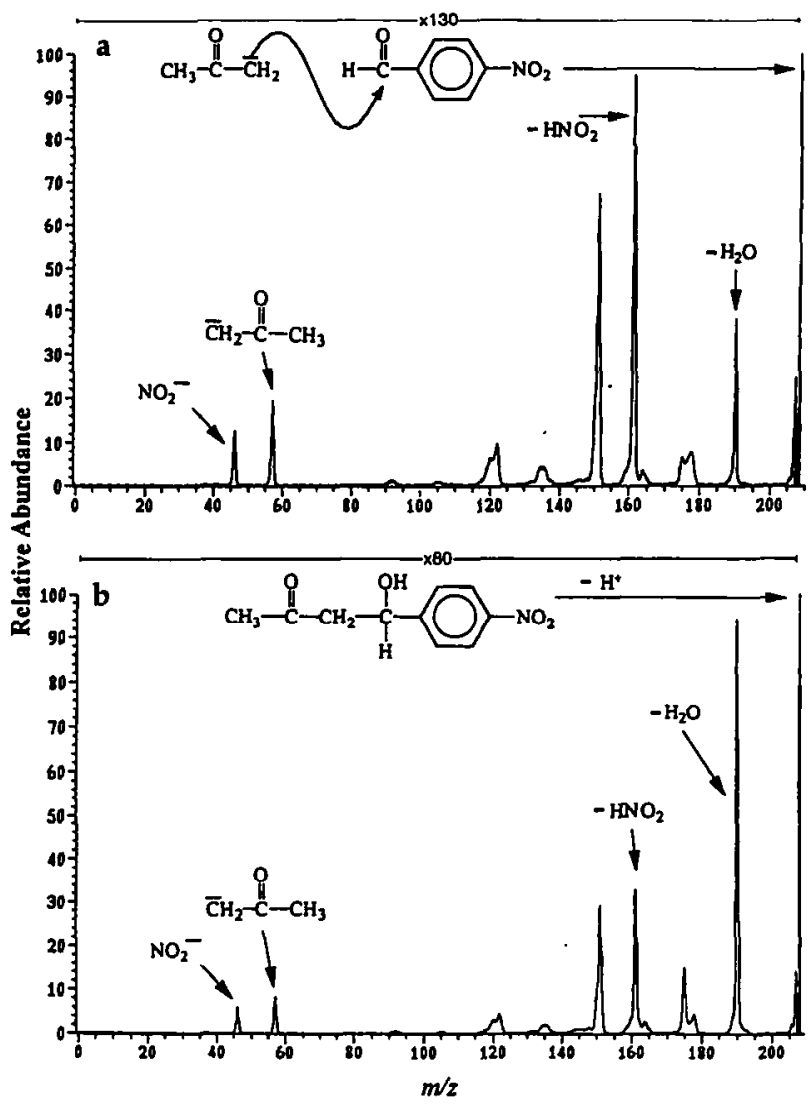

Figure 1. The CAD spectrum of the adduct (a) of $m / z 208$ formed by the reaction of acetone enolate anion with $p$-nitrobenzaldehyde and (b) of the deprotonated 4-( $p$-nitrophenyl)-4hydroxy-2-butanone of $m / z 208$.

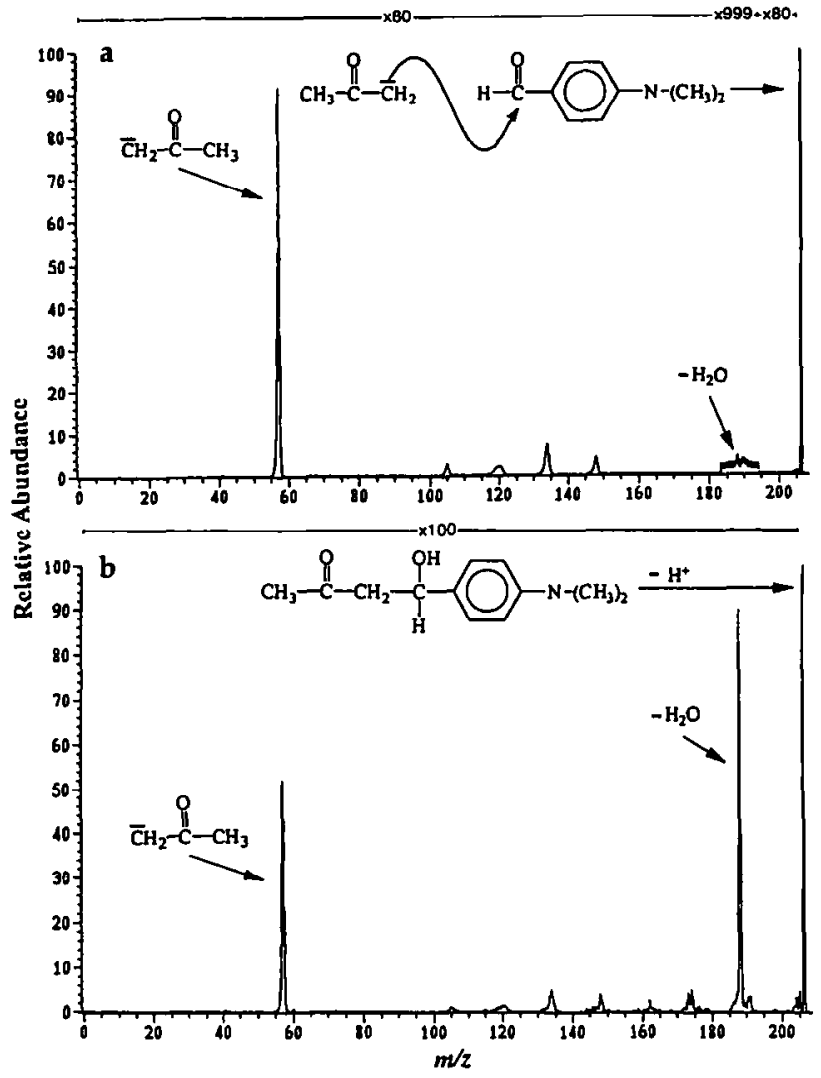

Figure 2. The CAD spectrum of the adduct (a) of $m / z 206$ formed by the reaction of acetone enolate anion with $p$-dimethylaminobenzaldehyde and (b) of the deprotonated 4 - $(p$-dimethylaminophenyl)-4-hydroxy-2-butanone of $m / z 206$.

Table 1. CAD mass spectra of the adduct ions from the ion-molecule reactions of acetone/ $p$-benzaldehydes and the $(\mathrm{M}-\mathrm{H})^{-}$ions of the reference $\beta$-hydroxy ketones ${ }^{\mathrm{a}}$

\begin{tabular}{|c|c|c|c|c|c|c|}
\hline \multirow[b]{2}{*}{ Substituent/system ${ }^{b}$} & \multicolumn{5}{|c|}{ Losses from adduct and $(\mathrm{M}-\mathrm{H})^{-}$ions (relative abundance) } & \multirow{2}{*}{$\begin{array}{c}\text { Formation of } \\
\mathrm{x}^{-}\end{array}$} \\
\hline & $\mathrm{H}$ & $\mathrm{H}_{2}$ & $\mathrm{H}_{2} \mathrm{O}$ & $\mathrm{X}^{\cdot} \mathrm{C}_{6} \mathrm{H}_{4}-\mathrm{CHO}$ & $\left(\mathrm{CH}_{3}\right)_{2} \mathrm{CO}$ & \\
\hline$-\mathrm{NO}_{2} / \mathrm{IMR}$ & 65 & 3.2 & 100 & 47 & 62 & 33 \\
\hline$-\mathrm{NO}_{2} /$ Ref & 15 & 2.6 & 100 & 8.2 & 11 & 6.2 \\
\hline$-\mathrm{Br} / \mathrm{IMR}$ & 46 & 21 & 47 & 100 & 16 & 11 \\
\hline$-\mathrm{Br} / \mathrm{Ref}$ & 17 & 10 & 100 & 15 & 3.5 & 4.0 \\
\hline$-\mathrm{Cl} / \mathrm{IMR}$ & 8.5 & 16 & 37 & 100 & 10 & 1.7 \\
\hline$-\mathrm{Cl} / \operatorname{Ref}$ & 7.4 & 12 & 100 & 33 & 3.5 & 1.0 \\
\hline$-\mathrm{SCH}_{3} / \mathrm{IMR}$ & 3.0 & 11 & 14 & 100 & 8.6 & \\
\hline$-\mathrm{SCH}_{3} / \operatorname{Ref}$ & 6.2 & 8.2 & 100 & 22 & 2.8 & \\
\hline$-\mathrm{H} / \mathrm{IMR}$ & 7.8 & 8.4 & 8.9 & 100 & 1.3 & \\
\hline$-\mathrm{H} /$ Ref & 11 & 9.5 & 100 & 36 & 0.44 & \\
\hline$-\mathrm{CH}_{3} / \mathrm{IMR}$ & 5.0 & 10 & 6.1 & 100 & 36 & \\
\hline$-\mathrm{CH}_{3} /$ Ref & 6.9 & 9.0 & 100 & 35 & 13 & \\
\hline$-\mathrm{OCH}_{3} / \mathrm{IMR}$ & 0.86 & 3.4 & 1.5 & 100 & 6.9 & \\
\hline$-\mathrm{OCH}_{3} /$ Ref & 2.6 & 11 & 100 & 20 & 0.86 & \\
\hline$-\mathrm{N}\left(\mathrm{CH}_{3}\right)_{2} / \mathrm{IMR}$ & 1.0 & 0.77 & 0.30 & 100 & 4.4 & \\
\hline$-\mathrm{N}\left(\mathrm{CH}_{3}\right)_{2} /$ Ref & 4.9 & 3.4 & 100 & 50 & 4.3 & \\
\hline
\end{tabular}

${ }^{a}$ Not all fragmentations associated with the para substituent for both adduct and reference ions are given

bIMR indicates an ion-molecule reaction; ${ }^{c}$ Ref indicates the appropriate reference compound. 
$\mathrm{HNO}_{2}$ from both the nitro-substituted adduct and the corresponding deprotonated reference compounds are omitted from the table because the other adducts and the deprotonated reference compound have para substituents that are not eliminated to appreciable extents.

\section{Formation of the Acetone Enolate Anion}

The major fragment ion observed consistently in the CAD spectra of the adducts of the gas-phase Claisen-Schmidt reactions is the acetone enolate of $m / z 57$. The deprotonated reference compounds show a markedly lower propensity to form this enolate. Confirmation that the anion of $\mathrm{m} / \mathrm{z} 57$ is the acetone enolate was obtained by sequential collisional activation $\left(\mathrm{MS}^{3}\right.$ ) experiments, which are designed to examine an ion that is a product of a decomposition reaction [24]. The precursor is selected and activated to produce the product of interest. Upon consecutive activation, the product is examined by either its metastable-ion or collisionally activated decompositions. Although the $\mathrm{MS}^{3}$ experiments suffer from poor sensitivity, they permit both the selection of the putative enolate, formed from either the collision-stabilized adduct or the deprotonated reference compounds, and the acquisition of its CAD spectrum. For example, the CAD spectra of the $m / z 57$ ions from the deprotonated 4-phenyl-4-hydroxy-2-butanone and of the adduct from the appropriate ion-molecule reaction are nearly identical to that of the authentic acetone enolate, which was formed from acetone by deprotonation with ${ }^{-} \mathrm{OCH}_{3}$.

The loss of neutral benzaldehyde to form the acetone enolate from the deprotonated reference compounds occurs via a retro-aldol mechanism from structure 1 in eq 1. Aldol-condensation products in the liquid phase, under the right conditions, also undergo a retrograde reaction to reform reactants.

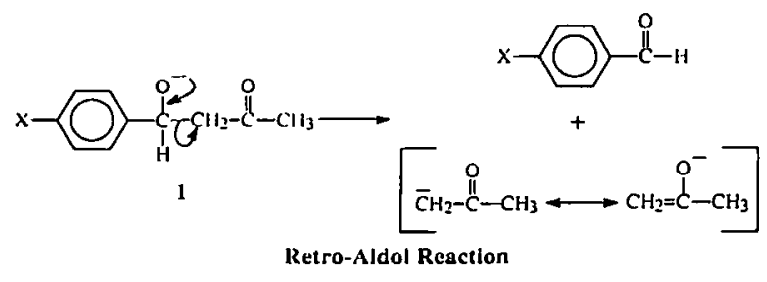

Structure $\mathbf{1}$ is produced directly by abstraction of $\mathrm{H}^{+}$by $\mathrm{CH}_{3} \mathrm{O}^{-}$, but abstraction of $\mathrm{H}^{+}$can occur from other sites, generating structures 2 and 3, for example. These latter structures form because the conjugate base of $\mathrm{CH}_{3} \mathrm{OH}$ is stronger than the anions $(1,2$, and 3). The gas-phase acidity $\left(\Delta G_{\text {acid }}\right)$ of $\mathrm{CH}_{3} \mathrm{OH}$ is $1565 \mathrm{~kJ} / \mathrm{mol}$ [25], whereas the gas-phase acidities that govern the ionization of the hydroxyl proton (shown removed in 1), the proton located alpha to both the ketone and hydroxyl groups (shown removed in 2), and the proton from the methyl group located alpha to the ketone group (shown removed in 3 ) are not available for the compounds studied here. However, the gas-phase acidities should be comparable to those of the structurally similar compounds benzyl alcohol (1519 $\mathrm{kJ} / \mathrm{mol}$ ), acetylacetone $(1406 \mathrm{~kJ} / \mathrm{mol})$, and acetone $(1515 \mathrm{~kJ} / \mathrm{mol})$, respectively [25]. Although these compounds are not perfect models for $1-3$, the differences in acidity between 2 and 1 or 2 and 3 are significant. The most exothermic reaction is to abstract a proton alpha to the ketone and hydroxyl groups to form structure 2. Thus, the highest fraction of deprotonated species from the reference compounds is expected to be 2. Structures 2 and 3, however, cannot produce the acetone enolate directly without first undergoing proton transfer to form 1.

The adducts from the ion-molecule reactions, as mentioned earlier, also decompose to give the acetone enolate, but with greater facility than do the reference $(\mathrm{M}-\mathrm{H})^{-}$ions. The increased abundance of the enolate formed from the Claisen-Schmidt reaction adduct is attributed partially to preferred production of $\mathbf{1}$, referred to as the tetrahedral intermediate. This structure can generate the acetone enolate directly, whereas structures 2 or 3, which are not formed directly but require a proton transfer, cannot. There is a population of structures 1-3 associated with the adducts that is different than that formed by deprotonation of the reference compounds. Structure $\mathbf{1}$ is preferred for the adducts, whereas ion 2 is favored thermodynamically by approximately $84 \mathrm{~kJ} / \mathrm{mol}$, and it fragments principally by expelling water but not undergoing the retroaldol reaction.

Facile production of the acetone enolate also can be envisioned to occur through a simple fragmentation of loosely bound adducts such as the ion-neutral complexes 4 and 5 or the proton-bound complexes 6 . For a review of these species in which an ion is coordinated to a neutral molecule or radical by weak forces such as ion-dipole attraction, the reader is directed to several excellent reviews [26]. Loosely bound adducts were proposed previously by Gross and co-workers [18, 19] to occur in similar aldol condensations and in Reformatsky reactions. Structures 4,5 , and 6 are possible because the acetone enolate is released from the adducts, particularly from those with electronreleasing groups. Additional evidence for structures 4 and 6 is their property to fragment to a deprotonated benzaldehyde.

Another intermediate that can decompose readily to the acetone enolate would form through an oxygen attack (see eq 2). Even structures associated with 4, 5, and 6 , where the negative charge resides predominately on the oxygen, can dissociate to form the ace-

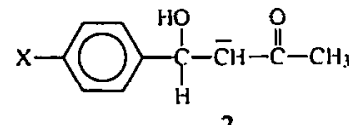

2

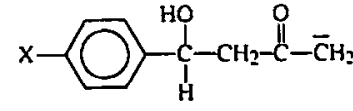

3 

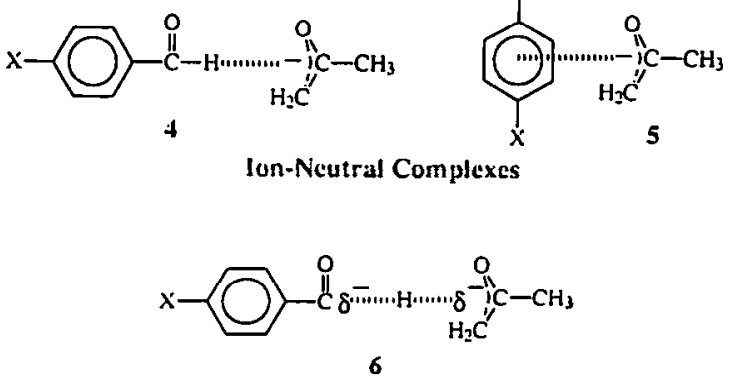

Proton-bound Complex

tone enolate. It is difficult to sort out these competing pathways for ion-molecule reactions, and this system is no exception. On the basis of CAD spectra of the adducts and deprotonated reference compounds, a small fraction of adducts that originates from oxygen attack of the acetone enolate at the carbonyl carbon of benzaldehyde cannot be ruled out. The elimination of water from 7 would be difficult to rationalize, and this is the topic of the next section.

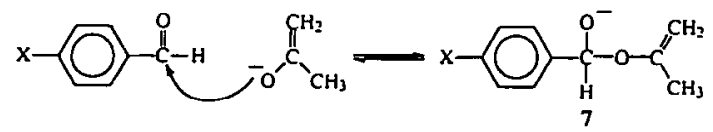

\section{Elimination of Water}

The elimination of water is the most facile reaction of the deprotonated reference compounds. The departure of $\mathrm{H}_{2} \mathrm{O}$ from $\beta$-dicarbonyl compounds [27] and from similar gas-phase aldol-condensation and Reformatsky reaction products was shown previously to be characteristic of a tetrahedral species. The route for water loss from the $\beta$-hydroxy ketones, however, was not elaborated for the deprotonated reference compounds or for adducts of structures similar to 1-3. We propose here that the elimination of $\mathrm{H}_{2} \mathrm{O}$ occurs predominantly from that fraction of covalently bound adducts that exist as structure 2. Water loss cannot occur from 1 directly without proton transfer to form 2 . Structure 3 can be envisioned to lose $\mathrm{H}_{2} \mathrm{O}$ via a charge-remote 1,2-elimination, but this is probably a less facile route than that for water elimination from 2. Elimination of $\mathrm{H}_{2} \mathrm{O}$ via a loosely bound adduct $(4,5$, or 6$)$ or through an oxygen-attack adduct (7) is highly unlikely.

The propensity for water elimination from the adduct becomes considerably attenuated as the electronreleasing character of the para substituent increases. Electron-withdrawing groups pull electron density from the carbonyl carbon of the benzaldehyde, which creates a greater partial positive charge on the carbonyl carbon and makes it more susceptible to nucleophilic attack. This effect is illustrated in eqs 3 and 4 for the reactions of $p$-nitrobenzaldehyde and $p$-dimethylaminobenzaldehyde, respectively, with the acetone enolate.
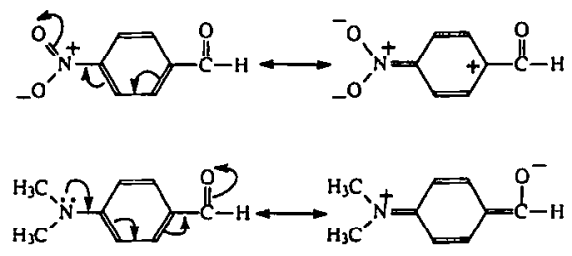

\section{Mechanism for Water Loss}

The mechanism for the elimination of water was investigated to determine the oxygen and hydrogens that are involved in the fragmentation. To determine which oxygen is involved, a CAD spectrum was obtained for the ion that is formed by loss of water from the adduct. The ion was produced in the ion source through the reaction of acetone and p-chlorobenzaldehyde. The spectrum of the adduct is nearly identical to that of the $\left(\mathrm{M}-\mathrm{H}-\mathrm{H}_{2} \mathrm{O}\right)^{-}$ion of the appropriate reference compound (see Figure $3 a$ for the CAD spectrum of the adduct from the ion-molecule reaction). The major fragments are a low abundance $m / z 41$ ion (probably the conjugate base of ketene) and those ions produced by losses of $\mathrm{CH}_{3}$ and $42 \mathrm{u}$ (most likely ketene). These fragment ions are consistent with elimination of the benzaldehyde carbonyl oxygen (i.e., the oxygen of the carbonyl involved in the nucleophilic addition) as part of the expelled water. The liquidphase Claisen-Schmidt reaction product also dehydrates analogously to give benzalacetone [28].

To verify that the putative (adduct $-\mathrm{H}_{2} \mathrm{O}$ ) ${ }^{-}$formed in the ion source is the same as the ion formed from the adduct, an $\mathrm{MS}^{3}$ experiment was conducted. The CAD spectra, obtained in the $\mathrm{MS}^{3}$ mode, of the (adduct $\left.-\mathrm{H}_{2} \mathrm{O}\right)^{-}$and of the $\left(\mathrm{M}-\mathrm{H}-\mathrm{H}_{2} \mathrm{O}\right)^{-}$of the reference compound are nearly identical. One difference is that $\mathrm{CH}_{3}$ is eliminated with greater propensity than when the source-produced (adduct $-\mathrm{H}_{2} \mathrm{O}$ ) and $\left(\mathrm{M}-\mathrm{H}-\mathrm{H}_{2} \mathrm{O}\right)^{-}$are activated (compare Figures $3 a$ and $b$ ). The spectra for the source-produced ions and

ions produced by collisional activation (CA) are different, possibly because the ions are formed under different conditions and, as a result, have different internal energy. This was tested by collisional activation of the source-produced $\left(\mathrm{M}-\mathrm{H}-\mathrm{H}_{2} \mathrm{O}\right)^{-}$ion in the first collision cell, and then selection of those activated but undecomposed ions for subsequent study. This was accomplished by suppression of the main beam by $80 \%$, as was done in the $\mathrm{MS}^{3}$ experiments, and closure of the beta slits after the first electrostatic analyzer to select the low translational-energy ions from the collisions. The spectrum of the energized $\left(\mathrm{M}-\mathrm{H}-\mathrm{H}_{2} \mathrm{O}\right)^{-}$ion from the adduct of the ion-molecule reaction is now similar to those of the ion-molecule and reference ions that are produced in the ion source (see Figure 3c). 

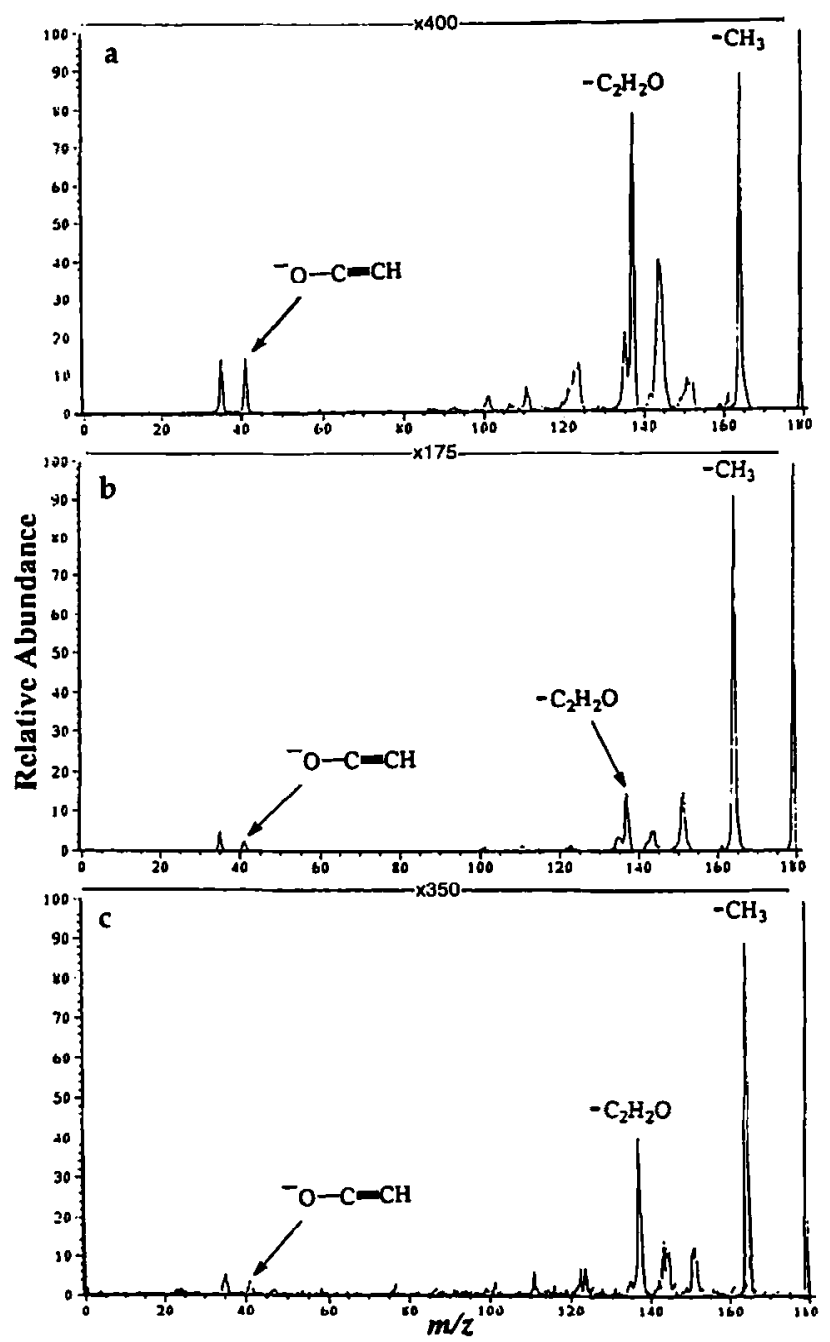

Figure 3. (a) CAD spectrum of the source-produced (adduct $\left.\mathrm{H}_{2} \mathrm{O}\right)^{-}$ion $(m / z 179)$ from the acetone $/ p$-chlorobenzaldehyde reaction. (b) CAD spectrum of the $\left(\mathrm{M}-\mathrm{H}-\mathrm{H}_{2} \mathrm{O}\right)^{-}$ion from 4-( $p$-chlorophenyl)-4-hydroxy-2-butanone obtained in the $\mathrm{MS}^{3}$ mode: $197 \rightarrow 179 \rightarrow$ products. (c) CAD spectrum of the sourceproduced (adduct $\left.-\mathrm{H}_{2} \mathrm{O}\right)^{-}$ion $(m / z \quad 179)$ activated by collisions in the first collision cell and activated for decomposition in the second collision cell.

The source-produced (adduct $-\mathrm{H}_{2} \mathrm{O}$ ) ${ }^{-}$ions from the reaction of acetone with $p$-nitrobenzaldehyde and the $\left(\mathrm{M}-\mathrm{H}-\mathrm{H}_{2} \mathrm{O}\right)^{-}$ions of the corresponding reference compounds also were investigated. Their CAD spectra are very similar and show that a facile loss of $\mathrm{CH}_{3}$ occurs just as it does in the $\mathrm{MS}^{3}$ experiments that involve the (adduct $\left.-\mathrm{H}_{2} \mathrm{O}\right)^{-}$of the reference compound. The CAD spectra of the source-produced and the CA-produced ions that come from water loss are nearly identical.

To discern the origin of the two hydrogen atoms on the departing water, acetone- $d_{6}$ was reacted with $p$ chlorobenzaldehyde to form an adduct of $\mathrm{m} / z 202$. The mass-to-charge ratio of the adduct is additional evidence that it is the acetone enolate anion that reacts in the ion source with the various $p$-substituted ben-

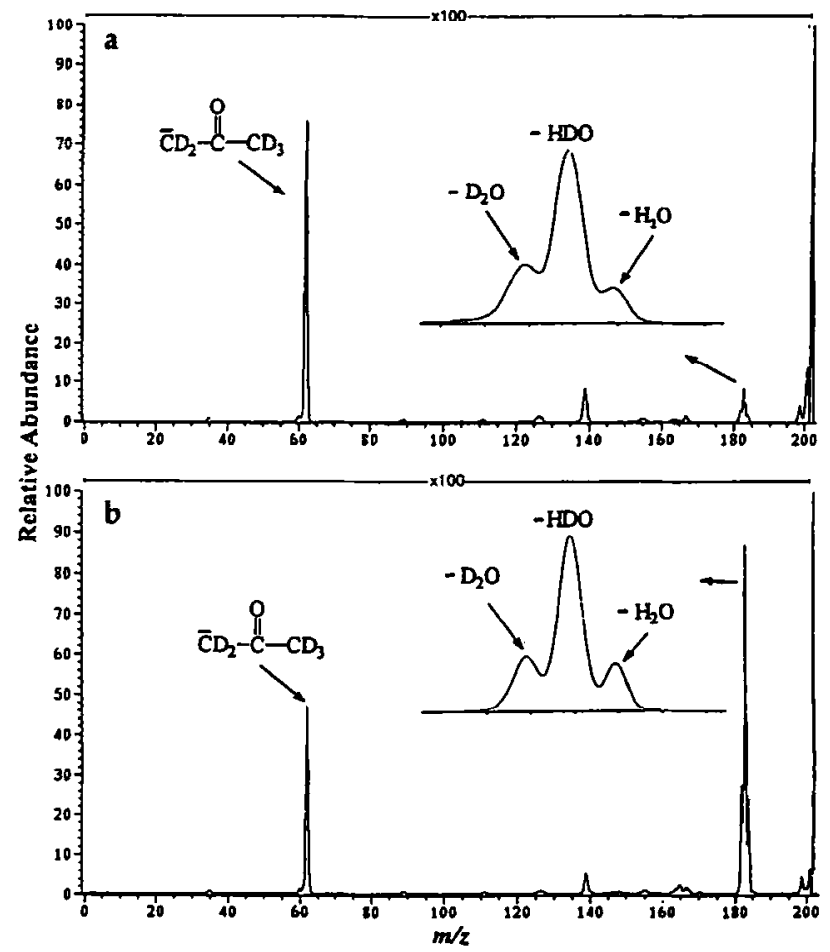

Figure 4. (a) CAD spectrum of the adduct of $\mathrm{m} / z 202$ formed in the reaction of acetone- $d_{6}$ enolate anion and $p$-chlorobenzaldehyde. (b) CAD spectrum of the deprotonated 4 -( $p$-chlorophenyl)-4-hydroxy-2-butanone-1,1,1,3,3- $d_{5}$ of $\mathrm{m} / \mathrm{z} 202$ (insets show expanded views of the region of the spectrum that contain peaks of $\mathrm{D}_{2} \mathrm{O}, \mathrm{HDO}$, and $\mathrm{H}_{2} \mathrm{O}$ losses).

zaldehydes. The CAD mass spectrum of the $m / z 202$ adduct (see Figure 4a) shows that $\mathrm{H}_{2} \mathrm{O}, \mathrm{HDO}$, and $\mathrm{D}_{2} \mathrm{O}$ are eliminated in a ratio of 1.2:5.0:1.75, respectively (average of four determinations). The deprotonated reference compound, 4-( $p$-chlorophenyl)-4hydroxy-2-butanone-1,1,1,3,3- $d_{5}$, eliminates $\mathrm{H}_{2} \mathrm{O}$, HDO, and $\mathrm{D}_{2} \mathrm{O}$ upon $\mathrm{CA}$ in a ratio of 1.3:5.0:1.5, respectively (see Figure $4 \mathrm{~b}$ ). For complete equilibration of hydrogen atoms, the ratio is 2.0:5.0:2.0. When we test other hypotheses that complete equilibration involves an equal number of exchangeable hydrogens and deuteriums that total eight, six, or four, we predict losses of $\mathrm{H}_{2} \mathrm{O}, \mathrm{HDO}$, and $\mathrm{D}_{2} \mathrm{O}$ in ratios of 1.87:5.00:1.87, 1.67:5.00:1.67, and 1.25:5.00:1.25, respectively. Other combinations that involve different numbers of hydrogens and deuteriums do not produce a match for the loss pattern.

One explanation for the observed water-loss pattern (see Scheme II) holds that elimination of water from the adduct begins with a proton transfer, which produces a hydroxyl group, followed by the formation of a carbon-carbon double bond and ejection of a hydroxyl ion to give an ion-neutral complex, 8 . When the reference compound is deprotonated by ${ }^{-} \mathrm{OCH}_{3}, 2$ can be formed directly. The $\mathrm{OH}^{-}$is held by an iondipole interaction and can abstract a proton from various positions. Abstraction from the vinylic positions forms complexes 9 or 12, whereas abstraction of an 


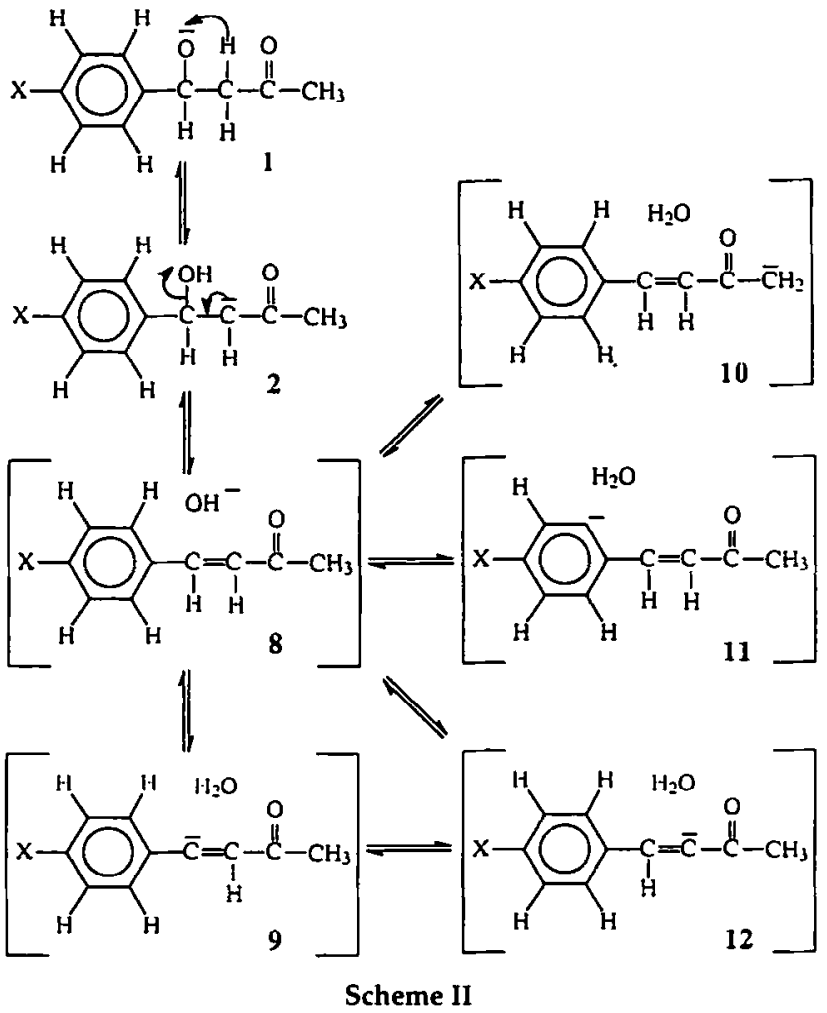

aryl proton generates 11 , and abstraction of a methylgroup proton produces 10 . The abstraction of a methyl proton is exothermic, and the resulting water can easily depart.

The removal of an aryl proton for the adducts and reference compounds studied here would normally be considered an endothermic process, but the ion-dipole interaction may return approximately $84 \mathrm{~kJ} / \mathrm{mol}$ as the two reactants begin to complex $[29,9 \mathrm{~d}]$. This interaction is particularly favored when the aromatic ring contains an electron-withdrawing group and explains, in part, the facile water loss from adducts formed from a benzaldehyde that bears an electron-withdrawing substituent. Some or all of the excess internal energy contained in the complex may be used to carry out the transfer, which forms 11. Subsequent proton transfer, which is exothermic, results in exchange of hydrogens prior to dissociation. DePuy and co-workers [30] showed that $\mathrm{OH}^{-}$exchanges with the protons of benzene- $d_{6}$ and that 2-phenylallyl anion exchanges eight of its nine protons (at least four of the five aromatic protons). There is a requirement that the acidity of the $\mathrm{C}-\mathrm{H}$ bond must be less than the ion-dipole energy of the ion-neutral complex.

The two processes, losses of $\mathrm{CH}_{3}$ and $42 \mathrm{u}$ (ketene) from the (adduct $\left.-\mathrm{H}_{2} \mathrm{O}\right)^{-}$and the reference $(\mathrm{M}-\mathrm{H}$ $\left.-\mathrm{H}_{2} \mathrm{O}\right)^{-}$ions, are indicative of at least two structures for these ions. Methyl loss can be envisioned to occur after water elimination from 9 and 12 (Scheme II), whereas ketene loss is expected to be a signature of the ion formed after water loss from 10. Recall that both the source-produced (adduct $\left.-\mathrm{H}_{2} \mathrm{O}\right)^{-}$and $(\mathrm{M}-\mathrm{H}-$
$\left.\mathrm{H}_{2} \mathrm{O}\right)^{-}$ions from the reference compounds give CAD spectra that indicate methyl loss and ketene elimination are significant (see Figure 3a). When the (adduct$\left.\mathrm{H}_{2} \mathrm{O}\right)^{-}$ion is formed through a CAD process or is collision-activated prior to acquisition of its CAD spectrum (see Figure $3 b$ and $3 c$, respectively), the loss of methyl dominate, which suggests that water elimination from structure $\mathbf{1 0}$ is not important.

Following proton transfer, water loss also can occur from 1 through a six-membered ring as shown in Scheme III, to form 3. However, this is an alternate route to 10 [the prime (') is used in Scheme III to denote an isomeric resonance structure); this route provides a means for water elimination and scrambling as shown in Scheme II.

\section{Elimination of $\mathrm{H}^{*}$ and $\mathrm{H}_{2}$}

The loss of $\mathrm{H}^{*}$ (not $\mathrm{D}^{\circ}$ ) occurs in both the metastable and collisionally activated decompositions of the adduct, formed by the reaction of acetone- $d_{5}$ enolate with various $p$-substituted benzaldehydes, and the deprotonated 4-( $p$-chlorophenyl)-4-hyd roxy-2butanone-1,1,1,3,3- $d_{5}$. The fragment presumably has structure 13 in eq 5 :

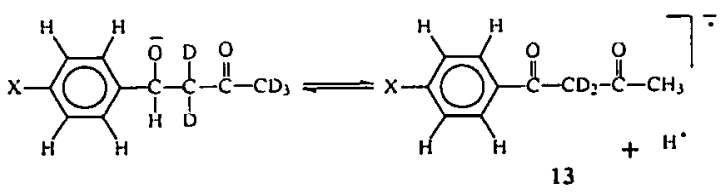

The loss of $\mathrm{H}_{2}$ (HD for the labeled adducts and deprotonated reference compounds) also can occur through the tetrahedral intermediate to give $\mathbf{1 4}$ shown in eq 6 :

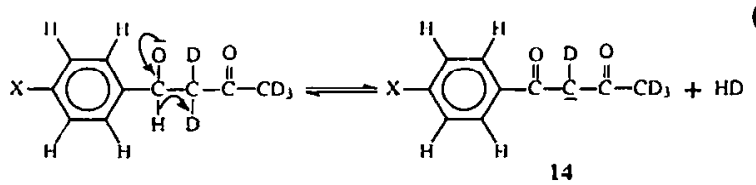

Indeed, the loss of $\mathrm{H}_{2}$ is indicative of fragmentation of an alkoxide as previously was reported for simple alkoxide anions [31]. The source-produced (adduct $\left.\mathrm{H}_{2}\right)^{-}$ions as well as the $\left(\mathrm{M}-\mathrm{H}-\mathrm{H}_{2}\right)^{-}$ions of the reference compounds, upon subsequent collisional ac-
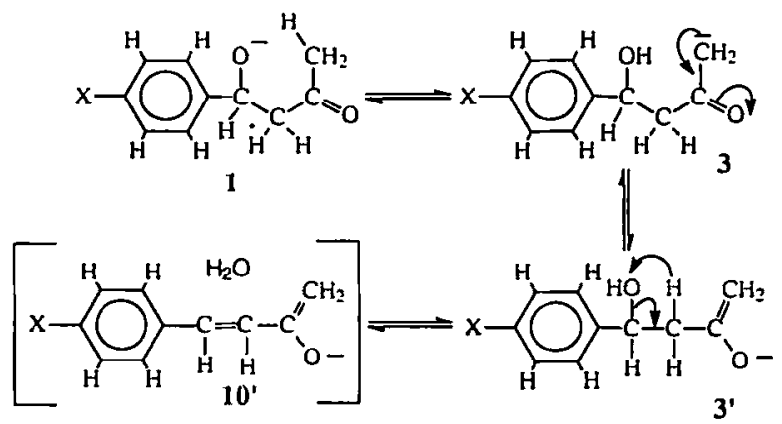

Scheme III 
tivation, eliminate predominantly $\mathrm{CH}_{2} \mathrm{CO}(42 \mathrm{u})$ and undergo losses of $\mathrm{CH}_{3}, \mathrm{CH}_{4}$, and $\mathrm{H}_{2} \mathrm{O}$, which are characteristic losses of $\beta$-dicarbonyl [27] aldolcondensation [18] and Reformatsky-condensation products [19].

The losses of $\mathrm{H}^{\circ}$ and $\mathrm{H}_{2}$ from adducts that contain electron-withdrawing groups are nearly the same as those from the $(\mathrm{M}-\mathrm{H})^{-}$ions of the reference compounds. This indicates that most of the adducts from reactions in which the benzaldehyde is electron-poor are bound covalently. For reactions of benzaldehydes with strongly electron-releasing substituents [e.g., $-\mathrm{OCH}_{3}$ and $\left.-\mathrm{N}\left(\mathrm{CH}_{3}\right)_{2}\right]$, the losses of $\mathrm{H}^{\cdot}$ and $\mathrm{H}_{2}$ from the adducts are diminished with respect to those from the references. Calculation reveals that approximately one third of these adducts for the reactions of the electron-rich benzaldehydes are bound loosely.

\section{Correlation with Hammett Constants}

The Hammett relationship is used here to elucidate the electronic effects of the substituents on the extent of formation of tetrahedral intermediates (i.e., those adducts that eliminate $\mathrm{H}_{2} \mathrm{O}$ ) in the gas-phase Claisen-Schmidt reaction. The Hammett equation (see eq 7) is one of the mainstays of quantitative structure-reactivity relationships in physical organic chemistry:

$$
\log \left(\frac{k}{k_{0}}\right)=\log \left(\frac{K}{K_{0}}\right)=\sigma \rho
$$

In eq $7, k$ and $K$ are the rate and equilibrium constants, respectively, for the reaction of a substituted benzene derivative, and $k_{0}$ and $K_{0}$ are the rate and equilibrium constants for the unsubstituted compound.

Although the Hammett correlation has been used to measure substituent effects for gas-phase reactions, Attina and Cacace [32] interjected a cautionary note on the validity of the approach. They argue that because the substituent constants are obtained from equilibrium and kinetic data for reactions in the liquid phase at well defined temperatures, they do not apply to ion-molecule and fragmentation reactions, which often are conducted at low pressures where the system is not characterized by a temperature. Nevertheless, the Hammett relation has been demonstrated to be useful to correlate gas-phase reactions that occur in mass spectrometers [33].

The Hammett $\sigma_{\mathrm{p}}$ parameter is used here to probe the extent of negative-charge stabilization provided by the para substituents of the benzaldehydes in their reaction with the acetone enolate. We expect the extent of stabilization to determine the fraction of tetrahedral intermediates in a mixed population of structures for the adduct "isolated" under the conditions of these experiments. The fraction that is a tetrahedral interme-
Table 2. Percent of tetrahedral adduct population that eliminates $\mathrm{H}_{2} \mathrm{O}$ with respect to adducts that produce acetone enolate

\begin{tabular}{lcc}
\hline \multicolumn{1}{c}{ Para substituent } & $\mathrm{FH}_{2} \mathrm{O}$ loss $^{\text {a }}$ & Sigma value \\
\hline \hline $\mathrm{NO}_{2}$ & $68 \pm 5$ & 0.778 \\
$\mathrm{Br}$ & $32 \pm 5$ & 0.232 \\
$\mathrm{Cl}$ & $27 \pm 3$ & 0.227 \\
$\mathrm{SCH}_{3}$ & $12 \pm 1$ & 0 \\
$\mathrm{H}$ & $8.2 \pm 2.0$ & 0 \\
$\mathrm{CH}$ & $5.7 \pm 2.7$ & -0.17 \\
$\mathrm{OCH}_{3}$ & $1.5 \pm 0.1$ & -0.268 \\
$\mathrm{~N}(\mathrm{CH})_{3}$ & $0.30 \pm 0.1$ & -0.83 \\
\hline
\end{tabular}

${ }^{a}$ Standard deviation was for two to five separate determinations.

diate is calculated from data in the adduct's CAD spectra by taking the abundance of the ions produced by water loss and dividing by the sum of the abundances of the acetone enolate and the anion produced by water loss.

The percent of tetrahedral adducts with respect to all other adducts of the Claisen-Schmidt reactions (see Table 2) correlates reasonably well with the Hammett sigma constants (see Figure 5; correlation coefficient is 0.921 and the $\rho$ value is +1.6 ). This reaction constant, which is a quantitative measure of the relative tendency to form a tetrahedral intermediate, is evidence that this gas-phase Claisen-Schmidt reaction is facilitated by electron-withdrawing substituents.

The deprotonated reference compounds do not show a correlatable trend for water elimination (see Table 1). Because the deprotonated reference compounds exist principally as $\mathbf{2}$, the water elimination is shielded from the electronic effects of the para substituents.

\section{Possibility of ipso Substitution}

Another route for attack of a nucleophile is on the benzene ring to give ipso substitution. Ipso substitu-

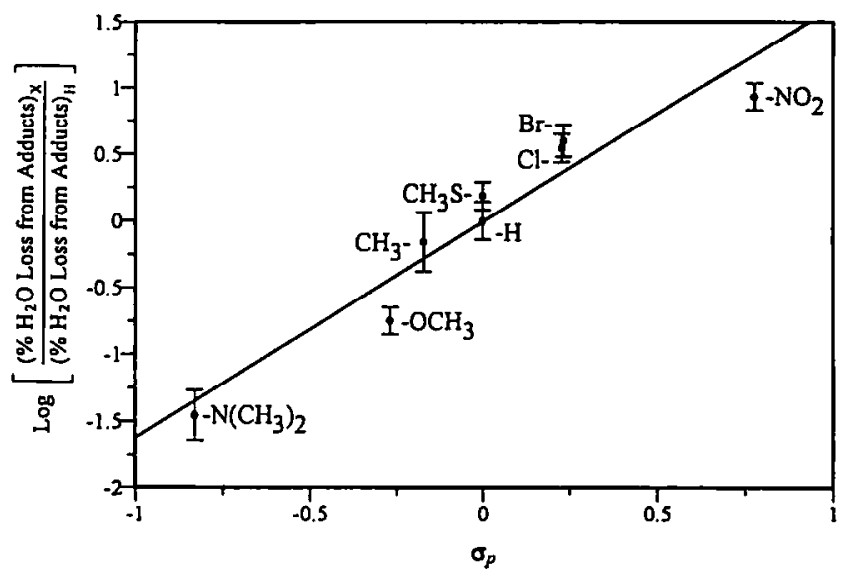

Figure 5. Hammett plot of the relative percent of tetrahedral intermediates (i.e., species that eliminate $\mathrm{H}_{2} \mathrm{O}$ ) with respect to all other adducts for the reactions of the acetone enolate anion with the various $p$-substituted benzaldehydes at approximately 0.1 torr $(13 \mathrm{~Pa})$ versus $\sigma_{\mathrm{p}}$. 
tion should be most favored for a benzaldehyde that has the strongest electron-withdrawing substituent. Thus, we examined closely the nature of the adduct produced in the reaction of the acetone enolate with $p$-nitrobenzaldehyde. This system has the highest fraction of adduct that exists as a tetrahedral intermediate and permits the closest comparison of the CAD spectra of the adduct and the $(\mathrm{M}-\mathrm{H})^{-}$of the reference compound. Upon collisional activation, both species give the same product ions in similar abundances (see Figure $1 \mathrm{a}$ and $\mathrm{b}$ ), which indicates that there is structural similarity between the adduct and the $(\mathrm{M}-\mathrm{H})^{-}$of the reference and rules out any significant ipso substitution.

When acetone- $d_{6}$ is reacted with $p$-nitrobenzaldehydc, the adduct loses $48 \mathrm{u}$, which corresponds to $\mathrm{DNO}_{2}$ (not $\mathrm{HNO}_{2}$ ). An ion-neutral complex would explain the abstraction of $\mathrm{D}$ by $\mathrm{NO}_{2}^{-}$. The deuterium probably originates from one of the two deuteriums located alpha to the ketone on the benzene-ring side of the alkyl chain because these are the most acidic. Furthermore, we obtained the CAD spectra of the (adduct $\left.-\mathrm{HNO}_{2}\right)^{-}$and of $\left(\mathrm{M}-\mathrm{H}-\mathrm{HNO}_{2}\right)^{-}$of the reference, by both tandem mass spectrometry and $\mathrm{MS}^{3}$, and found the spectra to be nearly identical. This also indicates that ipso substitution does not occur to any appreciable extent, but does not explain why various product ions observed in the CAD mass spectra of the ion-molecule-reaction adducts are of higher abundance than those of the appropriate reference $(M-$ $\mathrm{H})^{-}$ions (compare, for example, products from the loss of neutral acetone from the adduct and from the appropriate deprotonated reference compound; see Table 1). The difference may be due to a variation of the initially formed structures of the reference and adduct ions, as was discussed already.

\section{Conclusions}

The Claisen-Schmidt reaction of substituted benzaldehydes and the acetone enolate occurs in the gas phase to produce an isolatable tetrahedral intermediate along with other covalently bound and loosely bound complexes. The fraction of the tetrahedral adduct (i.e., the species that eliminates $\mathrm{H}_{2} \mathrm{O}$ ) is predictable on the basis of the Hammett relation. As the electron-withdrawing character of the para substituent of the benzaldehyde increases, the fraction of tetrahedral adducts also increases. This conclusion is consistent with the nature of the tetrahedral intermediate, structure 2, which is expected to undergo a more facile elimination of water than do other covalent adducts and loosely bound ion-dipole or hydrogen-bound complexes.

\section{Experimental}

The high-pressure experiments were carried out with a Kratos Scientific Instruments (Manchester, UK) MS50 triple analyzer mass spectrometer [34] of $\mathrm{E}_{1} \mathrm{BE}_{2}$ design (E denotes electrostatic sector analyzer; $B$ denotes magnet sector analyzer) equipped with a Kratos Mark-V chemical ionization source. The instrument was operated in the negative-ion mode at an accelerating voltage of $-8 \mathrm{kV}$, to give an ion-residence time in the source of $\approx 10 \mu \mathrm{s}$ [35]. Precursor-ion selection was performed at a resolving power of $\approx 5000$ unless interfering isobars were present; then the resolving power was increased to separate the ions. The methyl nitrite was leaked into the source through a Kratos reagent-gas inlet system to an indicated sourcehousing pressure of $\approx 7 \times 10^{-6}$ torr $\left(9 \times 10^{-4} \mathrm{~Pa}\right)$. Sufficient acetone was delivered to the source via a custom-fabricated reservoir probe equipped with a variable leak valve to give a source-housing pressure of $\approx 2 \times 10^{-5}$ torr $\left(3 \times 10^{-3} \mathrm{~Pa}\right)$. The liquid para-substituted benzaldehydes were introduced by a customfabricated heated glass inlet system via a molecular leak, whereas the solid benzaldehydes were vaporized directly into the source by heating a direct-insertion probe so that a pressure of $\approx 2 \times 10^{-5}$ torr $\left(3 \times 10^{-3}\right.$ $\mathrm{Pa}$ ) was achieved. An indicated source-housing pressure of $3-5 \times 10^{-5}$ torr $\left(4-7 \times 10^{-3} \mathrm{~Pa}\right)$ corresponded to a pressure inside the source chamber of approximately 0.1 torr $(13 \mathrm{~Pa})$.

The metastable-ion and collision-activated decomposition experiments were carried out by selecting the precursor ion with MS-1, which is comprised of $E_{1} B$, and scanning the voltage applied to $E_{2}$ of MS-2 to obtain a spectrum of the product ions. The CAD spectra were obtained after collision of the selected ion beam with sufficient helium introduced to the collision cell located in the third field-free region to cause a $50 \%$ reduction of the selected ion beam. The metastable-ion experiments were carried out by using the same procedure described for the CAD experiments except helium was not added to the collision cell. Each spectrum was the average of $10-50$ scans taken at a rate of $30 \mathrm{~s}$ per scan.

The $\mathrm{MS}^{3}$ experiments [24] also were conducted on the Kratos MS50 triple analyzer. The adduct ions from the reaction of the acetone enolate anion with the substituted benzaldehydes were activated in the first collision cell, located in the first field-free region, by collisions with sufficient helium to cause an $80 \%$ reduction of the ion-beam intensity. MS-1 was used to deliver the product ion of interest to the second collision cell in the third field-free region, where the beam intensity was suppressed by $50 \%$ with collisions with helium. The fragments from the selected product ion were analyzed by scanning MS-2. MS ${ }^{3}$ experiments with reference compounds were conducted by selecting $(\mathrm{M}-\mathrm{H})^{-}$ions in the first step.

\section{Materials}

The para-substituted compounds-4-nitrobenzaldehyde, 4-bromobenzaldehyde, 4-chlorobenzaldehyde, 
4-methylthiobenzaldehyde, benzaldehyde, $p$ tolualdehyde, $p$-anisaldehyde, 4-dimethylaminobenzaldehyde, acetone, and sodium hydroxide - were all obtained from the Aldrich Chemical Co. (Milwaukee, WI) and were used without further purification. The reference compounds were prepared by using a standard procedure [36]. The identities of the reference compounds were confirmed by their full-scan highresolution ( $R=10,000)$ electron ionization mass spectra, acquired with a Kratos MS50 double focusing mass spectrometer. Perfluorokerosene was introduced via a heated inlet to bring the source-housing pressure to $\approx 5 \times 10^{-5}$ torr. Calibration from $\mathrm{m} / \mathrm{z} 28$ to 700 was achieved at a scan rate of $10 \mathrm{~s}$ per decade of mass in a typical run. The reference compounds also were characterized by ${ }^{1} \mathrm{H}$ NMR spectrometery (General Electric, $300 \mathrm{MHz}$ ), and the spectra were consistent with the proposed structures.

The methyl nitrite was synthesized according to the procedure of Hartung and Crossley [37] and Hunt et al. [38].

\section{Acknowledgments}

This work was supported by the Midwest Center for Mass Spectrometry, a former National Science Foundation Regional Instrumentation Facility at the University of Nebraska (Grant CHE-90172250), and by the NIH Research Resource in Mass Spectrometry at Washington University (Grant 2P41RR0954).

\section{References}

1. Schmidt, J. G. Ber. Deutsch. Chem. Ges. 1880, 13, 2342; 1881, $14,1459$.

2. (a) Claisen, L.; Claparede, A. Ber. Deutsch. Chem. Ges. 1881, 14, 349; (b) Claisen, L. Ber. Deutsch. Chem. Ges. 1887, 20, 655; (c) Claisen, L. Justus Liebigs Ann. Chem. 1899, 306, 322; (d) Claisen, L.; Ponder, Ammalen 1884, 233, 139.

3. Fischer, E.; Tafel, J. Ber. Deutsch. Chem. Ges. 1887, 20, 1088.

4. (a) Augustine, R. L. Carbon-Carbon Bond Formation, Vol. 1; Marcel Dekker: New York, 1979; (b) Denmark, S. E.; Henke, B. R. J. Am. Chem. Soc. 1991, 113, 2177.

5. (a) Heathcock, C. H. Science, 1981, 214, 395; (b) Heathcock, C. H. In Comprehensive Carbanion Chemistry, Vol. 5B; Buncel, E.; Durst, T., Eds.; Elsevier: New York, 1984; p. 181; (c) Kim, B. M.; Williams, S. F.; Masamune, S. In Comprehensive Carbonion Chemistry, Vol. 5B; Buncel, E; Durst, T., Eds.; Elsevier: New York, 1984; p. 239; (d) Arnett, E. M.; Palmer, C. A. J. Am. Chem. Soc. 1990, 112, 7354; (e) Evans, D. A.; Nelson, J. V.; Vogel, E.; Taber, T. R. /. Am. Chem. Soc. 1981, 103, 3099; (f) Dubois, J. E.; Dubois, M. Chem. Commum. 1968, 1567; (g) Dubois, J. E.; Fellman, P. C. R. Acad. Sci. Ser. C 1972, 274, 1307; (h) Dubois, J. E.; Fellman, P. C. Tetrahedron Lett. 1975, 1255; (i) Zimmerman, H.; Traxler, M. J. Am. Chem. Soc. 1957, $79,1920$.

6. March, J. Advanced Organic Chemistry, Reactions, Mechanisms, and Structure, 3rd ed.; Wiley: New York, 1985.

7. (a) Omura, S., Ed. Macrolide Antibiotics; Academic Press: Orlando, 1984; (b) Westley, J. W. Polyether Antibiotics; Marcel Dekker: New York, 1982.

8. (a) Pine, S. H. Organic Chemistry, 5th ed.; McGraw-Hill: New York, 1987; (b) Patai, S. The Chemistry of the Carbonyl Group; Interscience Publishers: New York, 1966.
9. (a) Asubiojo, O. I.; Blair, L. K.; Brauman, J. I., J. Am. Chein. Soc. 1975, 97, 6685; (b) Olmstead, W. N.; Brauman, J. I. J. Am. Chem. Soc. 1977, 99, 4219; (c) Asubiojo, O. I.; Brauman, J. I. J. Am. Chem. Soc. 1979, 101, 3715; (d) Wladkowski, B. D., Lim, K. F.; Allen, W. D.; Brauman, J. I. J. Am. Chem. Soc. 1992, 114, 9136.

10. (a) Bartmess, J. E.; Hays, R. L.; Caldwell, G. J. Am. Chem. Soc. 1981, 103, 1338; (b) DePuy, C. H.; Grabowski, J. J.; Bierbaum, V. M. Science 1982, 218, 955; (c) Bowie, J. H. Mass Spectrom. Rev. 1984, 3, 1; (d) Bowie, J. H. Mass Spectrom. Rev. 1984, 3, 161.

11. (a) McMahon, T. B.; Kebarle, P. J. Am. Chem. Soc. 1976, 98 , 3399; (b) Bordwell, F. G.; Bartmess, J. E.; Hautala, J. A. J. Org. Chem. 1978, 43, 3095; (c) Lowry, T. H.; Richardson, K. S. Mechanism and Theory in Organic Chemistry, 3rd ed.; Harper \& Row: New York, 1987.

12. Brickhouse, M. D.; Squires, R. R. J. Phys. Org. Chem. 1989, 2, 389.

13. Brickhouse,M. D.; Squires, R. R. J. Am. Chem. Soc. 1988, 110, 2706.

14. Ingemann, S.; Nibbering, N. M. M.; Sullivan, S. A.; DePuy, C. H. J. Am. Chem. Soc. 1982, 104, 6520; (b) Freriks, I. L.; de Koning, L. J.; Nibbering, N. M. M. J. Am. Chem. Soc. 1991, $113,9119$.

15. Wladkowski, B. D.; Wilbur, J. L.; Zhang, M.; Brauman, J. I. J. Am. Chem. Soc. 1993, 115, 8833.

16. Bouchoux, G.; Hoppilliard, Y. Tetrahedron Lett. 1987, $28,4537$.

17. (a) Klass, G.; Bowie, J. H. Aust. /. Chem. 1980, 33, 2271; (b) Klass, G.; Sheldon, J. C.; Bowie, J. H. Aust. J. Chem. 1982, 35, 2471; (c) Sheldon, J. C. Aust. J. Chem. 1981, 34, 1189.

18. Hayes, R. N.; Grese, R. P.; Gross, M. L. J. Am. Chem. Soc. $1989,111,8336$.

19. Castle, L. W.; Hayes, R. N.; Gross, M. L. J. Chem. Soc. Perkin Trans. 2 1990, 267

20. Haas, G. W.; Hayes, R. N.; Gross, M. L. Proceedings of the 39th ASMS Conference on Mass Spectrometry and Allied Topics; 1991; p. 1637.

21. (a) Hammett, L. P. J. Am. Chem. Soc. 1937, 59, 96; (b) Hammett, L. P. Physical Organic Chemistry Reaction Rates, Equilibria, and Mechanisms, 2nd ed.; McGraw-Hill: New York, 1970.

22. (a) Beynon, J. H.; Saunders, R. A.; Williams, A. E. Table of Metastable Transitions for Use in Mass Spectrometry; Elsevier: London; (b) Beynon, J. H. Anal. Chem. 1970, 42, 97A; (c) Jennings, K. R. In Mass Spectrometry Teclmiques and Applications; Milne, G. W. A., Ed.; Wiley Interscience: New York, 1971; (d) Beynon, J. H.; Caprioli, R. M. Biochemical Applications of Mass Spectrometry; Walker, G. R., Ed.; Wiley Interscience; New York, 1972; (e) Cooks, R. G.; Beynon, J. H.; Caprioli, R. M.; Lester, G. R. Metastable lons; Elsevier: New York, 1973.

23. (a) McLafferty, F. W.; Sakai, I. Org. Mass Spectrom. 1973, 7, 971; (b) McLafferty, F. W. Tandem Mass Spectrometry; Wiley: New York, 1983.

24. Burinsky, D. J.; Cooks, R. G.; Chess, E. K.; Gross, M. L. Anal. Chem. 1982, 54, 295.

25. Lias, S. G.; Bartmess, J. E.; Liebman, J. F.; Holmes, J. L.; Levin, R. D.; Miallard, W. G. J. Phys. Chem. Ref. Datn, 1988, 17, 703, 725,687 .

26. (a) Bowen, R. D. Acc. Chem. Res. 1991, 24, 364; (b) Hammerum, S. In Fundamentals of Gas Phase Ion Chentistry; Jennings, K. R., Ed.; Kluwer Academic Publishers: Dordrecht, Netherlands, 1991; (c) McAdoo, D. J. Mass Spectrom. Rev. 1988, 7, 363; (d) McAdoo, D. J. Acc. Chem. Res. 1993, 26, 295; (e) Morton, T. H. Tetrahedron 1982, 38, 3195; (f) Longevialle, P. Mass Spectrom. Rev. 1992, 11, 157.

27. Hayes, R. N.; Bowie, J. C. Int. I. Mass Spectrom. Ion Phys. 1986, 71, 233. 
28. Solomons, T. W. G. Organic Chemistry, 3rd ed.; Wiley: New York, 1984.

29. (a) Kebarle, P. Ann. Rev. Phys. Chem. 1977, 28, 455; (b) Squires, R. R.; Bierbaum, V. M.; Grabowski, J. J.; DePuy, C. H. I. Am. Chem. Soc. 1983, 105, 5185.

30. (a) Squires, R. R.; Bierbaum, V. M.; DePuy, C. H. J. Am. Chem. Soc. 1981, 103, 4256; (b) Andrist, A. H.; DePuy, C. H.; Squires, R. R. J. Am. Chem. Soc. 1984, 106, 845.

31. (a) Tumas, W.; Foster, R. F.; Pellerite, M. J.; Brauman, J. I. /. Am. Chem. Soc. 1983, 105, 7464; (b) Hayes, R. N.; Sheldon, J. C.; Bowie, J. H.; Lewis, D. E. J. Chem. Soc. Pekin Trans. 1984, 1431.

32. Attina, M.; Cacace, F. Org. Mass Spectrom. 1991, 26, 807.

33. (a) McLafferty, F. W. Anal. Chem. 1959, 31, 477; (b) Bursey, M. M.; McLafferty, F. W. J. Am. Chem. Soc. 1966, 88, 529; (c) Bursey, M. M.; McLafferty, F. W. J. Am. Chem. Soc. 1966,
88, 4484; (d) McLafferty, F. W.; Bursey, M. M. J. Org. Chent. 1968, 33, 124; (e) Bursey, M. M. Org. Mass Spectrom. 1968, 1, 31; (f) McLafferty, F. W.; Wachs, T.; Lifshitz, C.; Innorta, C.; Irving, P. I. Am. Chem. Soc, 1970, 92, 6687; (g) Daishima, S.; Iida, Y.; Kanda, F. Org. Mass Spectrom. 1991, 26, 486.

34. Gross, M. L.; Chess, E. K.; Lyon, P. A.; Crow, F. W.; Evans, S.; Tudge, H. Int. J. Mass Spectrom. Ion Phys. 1982, 54, 43.

35. Harrison, A. G. Chemical lonization Mass Spectrometry, 2nd ed.; CRC Press; Boca Raton, 1992.

36. (a) Noyce, D. S.; Reed, W. L. J. Am. Chem. Soc. 1958, 80, 5539; (b) Noyce, D. S.; Reed, W. L. J. Am. Chem. Soc. 1958, 81, 624 and references therein.

37. Hartung, W. H.; Crossley, F. Organic Syntheses; Wiley: New York, 1936

38. Hunt, D. F.; Stafford, G. D., Jr.; Crow, F. W.; Russell, J. W. Anal. Chem. 1976, 48, 2098. 